\title{
Mathematical modelling of traction resistance of the improved opener of grain seeder
}

\author{
Gali S. Gumarov ${ }^{1}$, Vladimir V. Konovalov ${ }^{2, *}$, Amangeldy E. Sarsenov ${ }^{3}$, Zhanna K. Kubasheva ${ }^{3}$, and Abelshaek A. \\ Rakhimov $^{3}$ \\ ${ }^{1}$ Makhambet Utemisov West Kazakhstan state university, 090000 Uralsk, Kazakhstan \\ ${ }^{2}$ Penza State Technological University, 440000 Penza, Russia \\ ${ }^{3}$ Zhangir khan West Kazakhstan agrarian-technical university, 090000 Uralsk, Kazakhstan
}

\begin{abstract}
The object of the study is a double disc coulter with a pressure plate. The aim of the research was to simulate the operation of the double disc coulter using a grain seed drill as an example. Analytical dependencies for determining the traction resistance of the improved coulter are presented. The method of calculating the drag resistance of a double disc coulter with an original pressure plate installed on it is given. The components of the traction resistance balance have been determined and the dependence on the sowing depth has been established. 3D graphical dependences of the traction resistance of serial and advanced coulters on the speed and depth of its movement have been constructed based on the results of calculations. The main influence is the placement depth. Speed of movement of the seeder in the considered interval of its values does not render essential influence on traction resistance. Installation of an additional pressure plate increases traction resistance to $5 \%$.
\end{abstract}

\section{Introduction}

In agrarian production a variety of seeders are used for sowing crops [1-3], among which modern machine designs are used [4-7]. However, for the sowing of grain crops in the former USSR territories to the present day are widely used rather simple constructions and reliable in the work disc seeders SZ-3,6 of various modifications [8-10].

However, the discs of these seed drills do not create a tightly packed seedbed, required by agricultural requirements, therefore, do not provide seed seeds with the required moisture content; this is especially important in dry areas, and do not evenly distribute seeds at the depth of planting.

In this regard, it is important to improve the efficiency of the remaining and used crops of the CZ-3.6 brand through modernization and nodes and elements (in particular, coulters), which ensure higher crop yields.

The technical solution implemented in the NorthKazakhstan region of the Republic of Kazakhstan is based on the equipping of a discs with a removable clamping plate, which ensures the pressurization of the seed-bed and soil looseness, obtained on the basis of the development of Gorbachev S.P. 2013 [11].

A number of works [12-14] describing the operation of coulters and their elements are known. However, they do not fully describe the implemented coulter design.

The purpose of the research was to simulate the operation of the modernized twin-disc coulter of the SZ-
3.6 grain seed drill in order to calculate the traction resistance.

Comparison of hook force changes on the movement of basic and modernized seeders was carried out by graphic analysis of results of change of traction resistance values for the improved coulter at different speeds and depth of its movement.

\section{Materials and methods}

\subsection{Study object}

The research is carried out using the known positions of classical mechanics and the theory of sowing and planting machines, which allow to determine the design parameters of the pressure plate and the traction resistance of the working body.

Calculation of traction resistance of serial and advanced coulters is made. By results of calculations 3D graphic dependences of traction resistance of serial and improved coulters on speeds of movement and depth of its running are constructed.

\subsection{Research tools}

As the main modeling tool, a modern computer based on the Microsoft Windows 8 platform was used. The Corel DRAW Graphics Suite software package was used to work with graphic information. It was theoretically described and calculated in Microsoft Office Excel.

\footnotetext{
*Corresponding author: konovalov-penza@ rambler.ru
} 
Besides, drawing of dependency charts was carried out with the help of a graphical editor built into this program.

\section{Results}

The improved double disc coulter, equipped with clamping plate 2 (figure 1), consists of two flat discs 1 , ground around the circumference and attached to form a sharp corner.

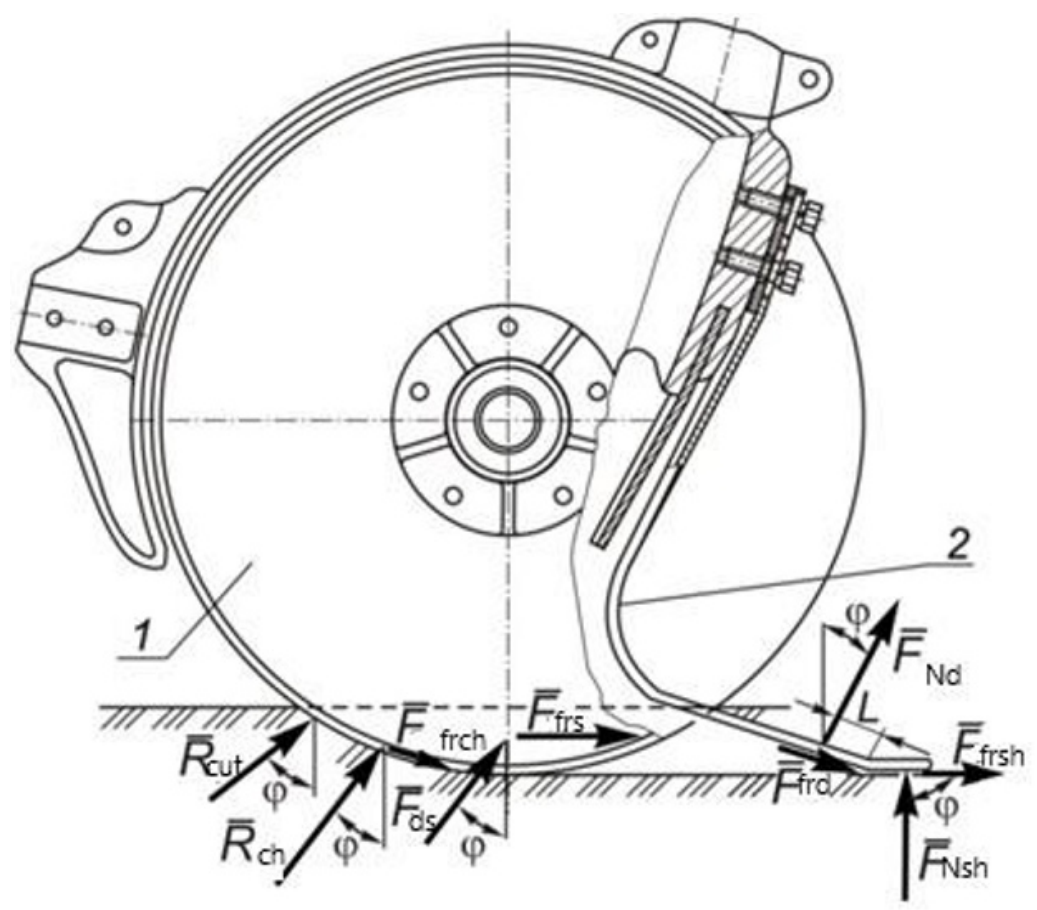

Fig. 1. Calculation scheme for determining the traction resistance of the advanced coulter: 1 - flat discs; 2 - pressure plate

During operation, the discs cut the soil. Each disc cuts its own soil layer to a certain depth and spreads the soil in a transverse direction, forming a groove. The pressure plate installed behind the discs, moving together with the coulter presses the seeds against the bottom of the furrow, thus leveling them on the depth of embedding, and thus crushing the lumps of soil that have fallen to the bottom [11].

At the same time, energy consumption for technological operation largely determines the efficiency of the applied machine and the cost of work performed. This component includes the hook force to move the seeder, which is determined by the coulter drag, which consists of the following components: rolling resistance $R_{\text {rol }}$ wheels loaded by the weight of the seeder on a loose inelastic surface prepared for sowing arable land; resistance $R_{\text {coul }}$ of coulters loaded into the soil; resistance $R_{\mathrm{fr}}$ friction in wheel bushings and mechanisms that transfer motion to the sowing shaft; resistance $R_{\mathrm{bl}}$ from accidental shocks and blows experienced by the drill during operation; working resistance $R_{\mathrm{dev}}$ rollers or other sowing unit devices.

Of these resistances, the first two are the most significant. According to the seed drill test data, they make up $92 . . .98 \%$ of the total traction force. The last two resistances have the smallest value and are expressed within one percent of the total [11].

The friction resistance of the RTRs in the wheel bushings and gearboxes can be expressed depending on the design of the lubrication system, but does not, on average, exceed two to three per cent of the total drag resistance of the seed drill.

On the basis of the above, let us focus on the main components of the resistance - the rolling resistance of the wheels and the movement of the coulters.

The rolling resistance of the wheel on the inelastic surface is mainly due to the work spent on deformation of the soil under the wheel, the work of soil crumpling. The determination of the work of under-wheel compaction depends on the size of the wheel (diameter $\mathrm{D}$ and width $\mathrm{b}$ of the rim) and, in addition, on the ability of the soil to resist compaction.

Soil resistance to buckling changes with the buckling depth of the buckling site. The regularity of such a change is expressed in the following form: $q=q_{0} \sqrt{h}$, where $q-$ voltage, $\mathrm{H} / \mathrm{m}^{2}$, corresponding to the immersion depth of the buckle site $F=1 \mathrm{~m}^{2}$, and $q_{0}-$ ratio of proportionality.

To determine the traction resistance of a seed drill with experimental coulters, the acad formula is applied. Goryachkina V.P. [12]:

$$
P=f_{\text {sum }} G+k_{s} a b n+\varepsilon a b n v^{2},
$$

where $f_{\text {sum }}$ - total coefficient of friction and rolling, $f_{\text {sum }}=0.2 \ldots 0.6 ; G-$ seed drill gravity, $\mathrm{H} ; k_{\mathrm{s}}-$ soil resistivity, $k_{\mathrm{s}}=2 \ldots 5 \cdot 10^{4} \mathrm{H} / \mathrm{m}^{2} ; a-$ coulter depth, $\mathrm{m} ; b-$ Maximum distance between coulter discs at field level; 
$n$ - number of coulters on the sowing machine; $\varepsilon-$ speed factor.

Since no other changes have been made to the seed drill design, we will calculate the traction resistance of the standard and advanced coulters from the above material $R_{\mathrm{s}}$. It consists of the following resistance forces (H): Cutting the blade $R_{\text {cut }}$, chamfering $R_{\mathrm{ch}}$, disc side $F_{\mathrm{ds}}$, friction of the side of the disc against the soil $F_{\text {frs }}$; clamping plate deformer $F_{\mathrm{d}}$, friction of the pressure plate deformer against the soil $F_{\text {frd }}$, indentation of seeds and soil mass by the shank of the pressure plate $F_{\text {shank }}$ and the friction forces of the shank of the pressure plate against the soil $F_{\text {frsh }}$ (figure 1 ).

Calculations to determine the traction resistance of the advanced coulter are based on the following

$$
\begin{aligned}
R_{s}=2 & \left(R_{\text {cut }}+R_{c h}+F_{\text {frch }}+F_{d s}+F_{\text {frs }}\right)+ \\
& +F_{d}+F_{\text {frd }}+F_{\text {shank }}+F_{\text {frsh }} .
\end{aligned}
$$

Let's consider the components of the equations.

Cutting resistance of the cutting edge $R_{\text {cut }}, \mathrm{H}$ [11]: $R_{\text {cut }}=K_{\text {cut }} \delta h$, where $K_{\text {cut }}-$ specific cutting resistance, $\mathrm{H} / \mathrm{m}^{2}$, for the prevailing soil type in Kazakhstan

$K_{\text {cut }}=60 \ldots 80 \mathrm{kH} / \mathrm{m}^{2} ; \delta-$ flat disk thickness, $\mathrm{m}, \delta=0.0025$ $\mathrm{m} ; h$ - disc travel depth equal to the seed placement depth of $0.05 \ldots 0.08 \mathrm{~m}$.

Resistance to chamfering of the ground part of the $\operatorname{disc} R_{\text {ch }}, \mathrm{H}$ [12]: $R_{c h}=F_{\text {frch }} \cos \theta f$, where $F_{\text {frch }}-$ the friction force of the ground chamfer; $\theta$ - disk chamfer angle, $\theta=18^{\circ} ; f-$ friction coefficient of soil on steel, $f=0.47$.

Friction of the soil in the chamfer $F_{\text {frch, }} \mathrm{H}[11]$ :

$$
F_{\text {frch }}=K_{\text {cut }} \delta h f \text {. }
$$

Also taken into account: friction force of the side surface of the disc against the soil $F_{\text {frs }}$, resistance force of the pressure plate deformer, friction force of the pressure plate deformer against the soil, resistance force of the pressure plate shank to penetration of seeds and soil mass, resistance force of the soil deformation by the side surface of the disk.

Changes in speed are not taken into account in the approximate calculations, considering the drag resistance to be proportional to the working width: $R_{h}=K B$, where $K$-machine resistivity, $\mathrm{kN} / \mathrm{m}$, for trailed seed drill $\mathrm{K}=1.0 \ldots 1.5 \mathrm{kN} / \mathrm{m} \mathrm{[12]}$; $\mathrm{B}$ - machine working width, $\mathrm{m}$.

Calculations were made in accordance with agrotechnical requirements, i.e. the sowing speed of the sowing unit during sowing should be in the range from 1.94 to $2.5 \mathrm{~m} / \mathrm{s}$, and the sowing depth for dry areas is recommended to accept 0.06 to $0.08 \mathrm{~m}$.

According to the results of calculations, threedimensional graphical dependences of traction resistance of serial and improved coulters in the above mentioned ranges of travel speeds and depth of travel of coulters are constructed (Figures 2 and 3).

Specific resistance $\mathrm{K}$ depends not only on the resistance of the coulters but also on the resistance of the sowing wheels to rolling, which in its turn depends on the type and parameters of the wheels, the load on them, resistance to rotation of sowing machines, etc..

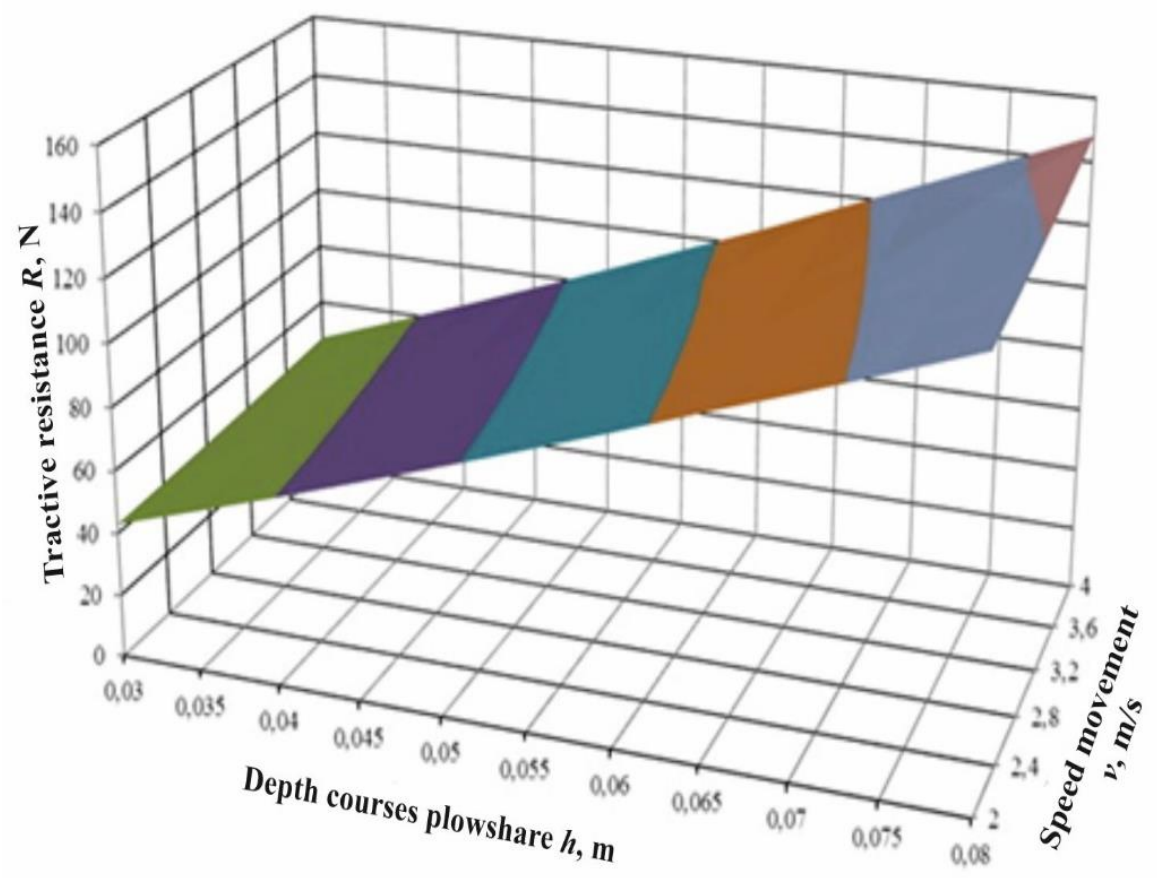

Fig. 2. Theoretical dependence of traction resistance for a serial coulter 


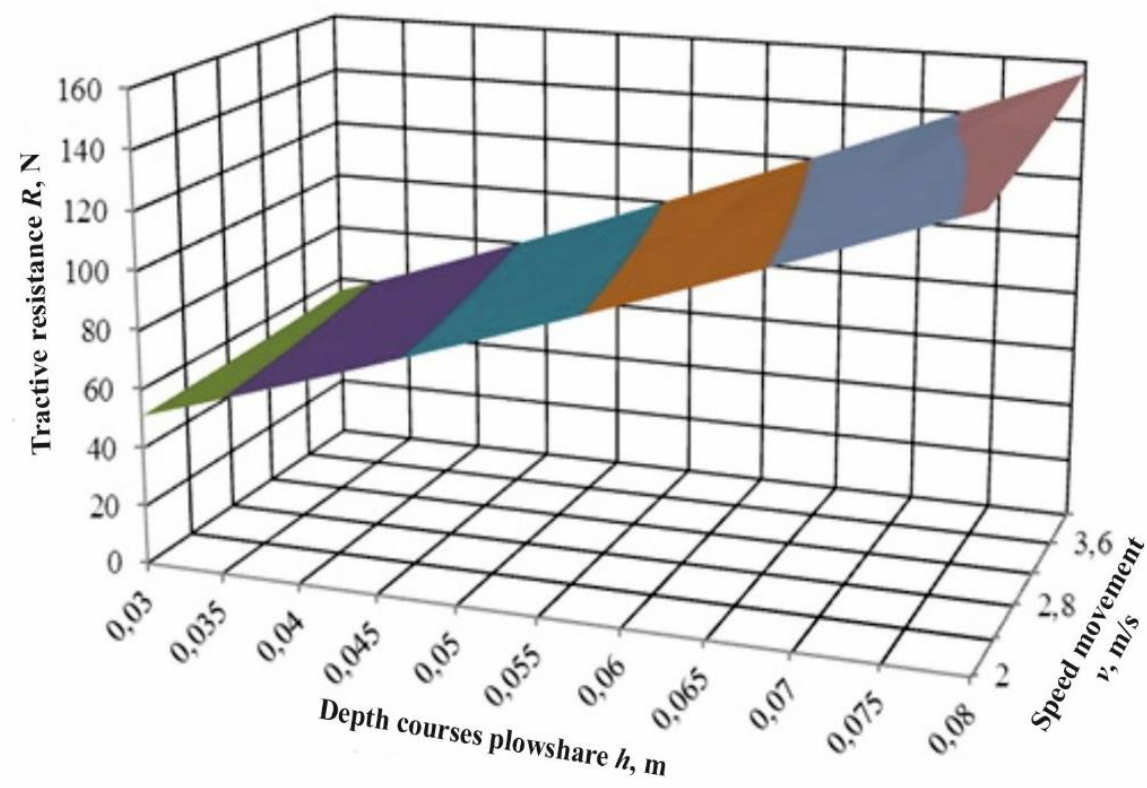

Fig. 3. Theoretical dependence of traction resistance for an improved coulter

\section{Conclusion}

The calculations made and the calculation method obtained on their basis allow to make a conclusion that the traction resistance of the sowing machine mainly depends on the technological properties of the soil, working width (number of coulters) and sowing depth. The main influence is the placement depth of the sowing material. Speed of movement of the seeder in the range of its values does not have a significant impact on the traction resistance.

Due to the pressure plate setting, the improved coulter pull resistance of the improved coulter increases the coulter pull resistance by $8 \mathrm{~N}$ compared to the standard one, which increases the pull resistance by up to $5 \%$.

Results of researches can be used by research institutes, design and design organizations at working out of new grain seeders, and the received values of traction resistance of the improved coulter will be useful at a choice of structure of sowing units and a loop of cars.

\section{References}

1. V. Kumar, C. Durairaj, Influence of Head Geometry on the Distributive Performance of Air-assisted Seed Drills, J. of Agricult. Engineer. Res.,75, 81 (2000) DOI: 10.1006/jaer.1999.0490

2. V.E. Saitov, R.F. Kurbanov, A.N. Suvorov, Assessing the adequacy of mathematical models of light impurity fractionation in sedimentary chambers of grain cleaning machines, Procedia Engineer., 150, 107-110 (2016) DOI: 10.1016/j.proeng.2016.06.728

3. S. Mudarisov et al., Specifying Two-Phase Flow in Modeling Pneumatic Systems Performance of Farm Machines, J. of Mechan.l Engineer. Res. and
Developm., 40(4), 706-715 (2017)

DOI: 10.7508/jmerd.2017.04.018

4. X. Lei, Y. Liao, Q. Zhang, L. Wang, Q. Liao, Numerical simulation of seed motion characteristics of distribution head for rapeseed and wheat, Comput. and Electr. in Agricult., 150, 98 (2018) DOI: 10.1016/j.compag.2018.04.009

5. A. Yatskul, J.-P. Lemière, F. Cointault, Influence of the divider head functioning conditions and geometry on the seeds distribution accuracy of the air-seeder, Biosyst. Engineer., 161, 120 (2017) DOI:10.1016/j.biosystemseng.2017.06.015

6. J. Chang, X. Zhang, Design and test of one-step centralized type pneumatic seeding system, Transact. of the Chinese Society of Agricult. Engineeri., 27, $136 \quad$ (2011) DOI: 10.3969/j.issn.1002-6819.2011.01.021

7. M.N. Chatkin, V.A. Ovchinnikov, Results of research of the beet seeder CCT-12 on alfalfa seed sowing, Vestnik of Saratov State Univer. named after N.I. Vavilov, 3, 68-69 (2007) Retrieved from: http://elibrary.ru/item.asp?id=9513629

8. A.M. Petrov, N.P. Kryuchin, Development of the universal pneumatic seed drill for grain, fine seeds and hard-to-sow crops, Proceedings of Samara State Agricult. Acad., 3, 3-7(2014)

9. N.P. Lariushin, A.V. Machnev, Results of the laboratory research of the coulter with the springloaded distributor and the furrow bottom copying device, Sci. review, 17, 33-39(2015)

10. V.R. Petrovets, V.I. Ilyin, V.A. Gaidukov, Comparative studies of the SZ-3,6A-08 and SZ-3,6 seed drills with experimental and serial coulters on different soil types, Design, use and reliab. of agricult. Machin., 1(16), 42-46(2017) 
11. I.M. Pavlov, A.V. Peretyatko, A.E. Sarsenov, Increase of the disc coulter efficiency, Agrar. Sci. J., 12, 58-60(2016)

12. V.I. Kurdyumov, E.S. Zykin, V.V. Artemyev, Theoretical substantiation of the force required to move the crest seeder section, Innovat. technique and technol., 3(12), 8-12(2017)
13. K.Z. Kukhmazov, A.I. Zyabirov, E.K. Tsibizov, Theoretical substantiation of the parameters of the sugar beet sowing coulter press roll, Niva Volga region, 2(43), 67-70(2017)

14. S.P. Gorbachev, Improving the quality of seed placement in grain crops by improving the disc coulter, $\mathrm{PhD}$ dissertation thesis (Volgograd, 2013) 